\title{
Comparison of Nonlinear Excitation Controllers for Power System Stabilization
}

\author{
Ayokunle A. Awelewa' ${ }^{1}$ Olawale Popoola²; Isaac A. Samuel ${ }^{3}$; Ayobami A. Olajube \\ ${ }^{1}$ Postdoctoral Fellow, Center for Energy and Electric Power, Department of Electrical Engineering, \\ Tshwane University of Technology, South Africa. \\ ${ }^{2}$ Director, Center for Energy and Electric Power, Department of Electrical Engineering, \\ Tshwane University of Technology, South Africa. \\ ${ }^{3,4}$ Lecturers, Department of Electrical and Information Engineering, Covenant University, Nigeria.
}

ORCID: 0000-0002-4409-6628 (Ayokunle), ORCID: 0000-0001-8010-4835(Isaac)

\begin{abstract}
The aim of this paper is to construct nonlinear synchronous generator excitation controllers and compare their effects on the dynamic performance of a single machine-connected-to-aninfinite- bus system. Two of these controllers are derived from the universal sliding mode control structure, while the third one is a modified form of the finite-time state homogeneity controller. The performance of the system under the action of these controllers is investigated through the application of a three-phase symmetrical fault at the infinite bus. Simulation results presented for various fault durations of 9, 14.5, 14.7, and 15 cycles show that all the controllers (which can be practically realized using fast power semiconductor devices in a staticexciter structure) perform well, with the homogeneity-based controller exhibiting the best robustness ability.
\end{abstract}

Keywords: Control laws, fault clearance time, homogeneous control, output function, relative degree, sliding mode control

\section{INTRODUCTION}

Power system oscillations such as local plant and inter-area occur in power systems and pose major challenges to power system control engineers. These oscillations are usually caused by lack of sufficient generator rotor damping torque (and this phenomenon characterized the earliest exciter/AVR due to the increase in bandwidth associated with the AVR loop) [1, 2]. The challenges become more stringent as power systems undergo changes due to network alterations (caused by faults or switching events) and/or variations in loads. Conventionally, power system stabilizers (PSSs), which may be single-or double-input, have been employed to handle these oscillation problems. They are complementary excitation controllers which provide positive damping torque to improve the overall generator rotor damping [3-11]. To some degree, they have performed satisfactorily well, but it has been noted that in the same way that a power system stabilizer can improve stability if tuned properly, it also has the ability to destabilize a generator's operation if incorrectly tuned" [2]. Thus, serious outstanding issues regarding the tuning of the conventional power system stabilizers and its performance for a wide range of operating conditions still remain [12]. However, many control techniques have been developed to enhance the performance of the conventional PSSs; they range from adaptive, robust, feedback linearization, to intelligent control strategies, with combinations of these strategies or their modifications having been implemented. Adaptive control strategies, such as model reference adaptive control (MRAC) and self-tuning control (STC), have been offered as solutions for providing adjustment of controller parameters as systems undergo changes due to parameter variations - they adjust their parameters on-line in response to changing operating conditions [13]. More commonly used is the self-tuning adaptive control, which comprises an approximator for on-line parameter identification, and a controller structure for guaranteeing good stability and dynamic response. Ghandakly \& Farhoud [4] proposed a self-tuning regulator for power system stabilizers using a recursive least squares identification technique, and a parameter optimization approach which employed a quadratic performance criterion. This regulator was shown to outperform the previously designed regulators based on minimum variance, generalized minimum variance, PID, and deadbeat control strategies [14-17], but the machine considered was represented by the classical swing-equation model with a first-order exciter, and subjected to a three-phase fault of duration not more than $0.1 \mathrm{~s}$. The speed response, it was shown, settled within 2-3s. Also, by employing a pole-shifting factor to make all closed-loop poles remain within the unit circle, Ghandakly \& Dai [18] demonstrated the effectiveness and robustness of a generalized multivariable self-tuning controller. The controller was shown to settle the system response in about $2 \mathrm{~s}$ after subjecting the model power system used to a series of fault conditions. Moreover, a set of power system stabilizer schemes, using various control strategies, was considered by Falkner \& Hech [19], and, although the authors raised some pertinent issues (i.e., limited controller sophistication; set point tracking) which suggested further investigations into the controllers discussed, it was inferred by them that linear robust and fuzzy controllers performed best in comparison to linear power system stabilizer, and nonlinear robust and sliding mode controllers. Criteria based on unmodelled dynamics, parameter variations, measurement noise, and input disturbance were used to draw the inferences. Meanwhile, Abdel-Magid et al. [20] proposed a new method of tuning the conventional power system stabilizers using the 
genetic algorithm (GA) approach. In the study, the problem of stabilizing a set of plants, representing various operating conditions, was converted into a GA-based optimization problem in which the considered power system stabilizer's parameters (only three of them) were optimally tuned to stabilize the set of plants. However, the objective function used was formulated based on the eigenvalues that needed to be shifted/placed, thereby making accurate tracking of eigenvalues a necessary condition for the success of the parameter tuning. Besides, the settling time of the speed variations was as much as $2.4 \mathrm{~s}$ in some disturbance cases considered.

Another significant area of applications of control techniques for power system stabilization is feedback linearization control (FBLC), which involves the complete or partial transformation of nonlinear systems into equivalent linear ones that are amenable to linear control design techniques [21, 22]. Several versions of FBLC have been applied to the design of power system excitation control [23-26]. But Gan et al. [27] set out to address some major design issues associated with FBLC, such as knowledge of the equilibrium point of the power system, dependence on the topology of the power system, and lack of guarantee that terminal voltages would remain within their operating limits. The authors proposed an improved FBLC using a linear optimal state-space feedback and saturation-type nonlinear robust control strategies, although a single-axis model was employed and the rotor angle oscillations were damped out in a long duration of about 15s (after perturbing system under the action of the proposed controller). Associated with FBLC is the method of zero dynamics which allows the output function of any nonlinear system to be kept very close to zero using a nonlinear state feedback control. Mahmud et al. [28] used this method of zero dynamics for feedback linearizing excitation control for power systems. A disturbance in the form of change in the rotor angle operating point was applied, and it was observed that the speed deviation steadied to zero in $2.6 \mathrm{~s}$.

Other control principles and design techniques that have gained prominence in realizing control laws for power system stabilization are Lyapunov stability theory, passivity theory, optimal control theory, and variable structure control; they have been implicitly or explicitly used in designing control systems that led to good performance and reliable system behaviour [29-37]. Lyapunov-based control design involves searching for, or constructing, a candidate energy function that would guarantee asymptotic stability and the acceptable response of a closed-loop system [38]. Passivity theory is a method of constructing a Lyapunov function for a combination of some system's subsystems with known individual Lyapunov functions; it provides procedures for generating physically meaningful Lyapunov functions for dynamical systems as long as passivity properties are satisfied. This method of Lyapunov function was employed by Rui et al. [39] to design a novel excitation controller using the adaptive backstepping technique. The controller worked well by removing oscillations within $2.5 \mathrm{~s}$ from the system after the system was subjected to an 8-cycle fault. One general drawback with this approach is how to determine the Lyapunov function whose existence is not certain. In the case of optimal control, the thrust of the design is to maximize the performance of a dynamic system at a minimum cost; it consists of designing a control law that will give an optimal state trajectory such that a cost function, known as a performance index, is minimized [40, 41].

Variable structure control strategies have been known to offer robustness in the face of system uncertainty [42, 12, 43], and sliding mode control is highly useful in this regard. Using sliding mode control, Colbia-Vega et al. [44] designed a robust excitation controller for power systems. The controller caused system variables to converge to the equilibrium point in $2.5 \mathrm{~s}$ after the removal of a 5-cycle fault to which the system was subjected. Also, Huerta et al. [45] proposed a sliding mode speed stabilizer (SMSS)-sliding mode voltage regulator (SMVR) scheme which is similar to the classical AVR-PSS scheme. Although the performance of the proposed scheme depended on the proper coordination of the SMSS and SMVR blocks, the scheme offered better damping of oscillations than the AVR-PSS scheme. In the work, oscillations caused by a three-phase symmetrical fault lasting for 8 cycles were damped out in $1.5 \mathrm{~s}$ to $2.5 \mathrm{~s}$. Another application of sliding mode control to a single-machine infinite bus power system was carried out by Atabak and Saeed [46]. Their proposed controller was shown to outperform the conventional PSS, though, as pointed out by the authors, determining the controller gain involved a trial-and-error process. The theory of synergetic control, which is similar to sliding mode control, has also been applied to design excitation controllers-for example, Ping et al. [47] proposed an improved synergetic excitation controller for improving transient stability of power systems and voltage regulation performance. This work used a synergetic control signal to move the system variables to a manifold defined as $\psi$ $=0$ and then cause them to remain on this manifold at all times, thereby removing oscillations due to system faults. A 6-cycle three-phase fault to which the system was subjected led to oscillations that were damped out in $2 \mathrm{~s}$.

Recently, there has been a resurgence of research interest in the application of fuzzy logic and neural networks, or their combinations, to damping oscillations in power systems. For instance, in [48], an adaptive power system stabilizer based on a generalized neuron artificial neural network (GNANN) was presented, and shown to outperform the structures put forward in [49-51] which have 20 input layers, 20 hidden layers, and 1 output layer; 35 input layers and 1 output layer; and 30 input layers, 10 hidden layers, and 1 output layer, respectively. In the paper, the system, whose identifier and the controller was GNbased, was able to dampen out oscillations due to a three-phase fault in about 2-3s. The authors used only a single neuron to realize the system. Meanwhile, Yee \& Milanovic [52] offered a new intelligent approach, i.e., a fuzzy logic controller that uses a systematic analytical procedure in place of a priori expert knowledge/information, to stabilize both the power output and terminal voltage of a synchronous generator. But the effectiveness of the approach was demonstrated using only the swing-equation model of a synchronous generator and hinged on the premise that the loads must be static or that their dynamic responses are negligibly small compared to that of the generator. Likewise, a fuzzy logic-based power system stabilizer (FLPSS) was developed by Venkatesh \& Rao [53] to replace the classical power system stabilizer for a single machine connected to an infinite bus. In the work, the FLPSS 
was shown to damp out system oscillations faster than the classical PSS, though, for the application of a three-phase fault that lasted for 5 cycles, the FLPSS could only make system variables settle in about 20s. More recently, an alternative approach to damping rotor angle oscillations in power systems was proposed by Garima et al. [54]. Using high power semiconductor devices, the authors developed a hybrid power flow controller (HPFC) to be located at an appropriate point in the transmission system. The performance of the controller was tested with a three-phase fault of 0.02 (1.2cycles), 0.04 ( 2.4 cycles), 0.1 ( 6 cycles), and $0.2 \mathrm{~s}$ ( 12 cycles) durations. It was observed by the authors that the HPFC damped out oscillations and ensured system stability in 3.53, 3.7, 3.6, and 2.6s, respectively, for the above-given fault durations. It has been pointed out that the critical clearing time, which is the maximum fault cycle that a system can withstand without losing stability, is an important aspect of transient stability [55]. Therefore, it is still desirable to have controllers that can furnish the system with greater ability to withstand longer fault cycles and damp out system oscillations in a much shorter time.

A more compact nonlinear controller, which is universal and can be easily tuned for excellent system dynamic performance, is highly desirable - this universal controller is analogous to the popular universal linear PID controller structure which has become the de facto controller for many industrial control applications [56]. In this paper, three nonlinear excitation controllers are presented. Two of these controllers are based on the universal sliding mode controller, while the third is derived from the general finite-time homogeneity controller. These controllers are suitably modified to yield acceptable system performance under an abnormal condition created by a threephase symmetrical fault of various durations.

\section{MATERIALS AND METHODS}

The methodological framework for the excitation control system is shown in Fig. 1.

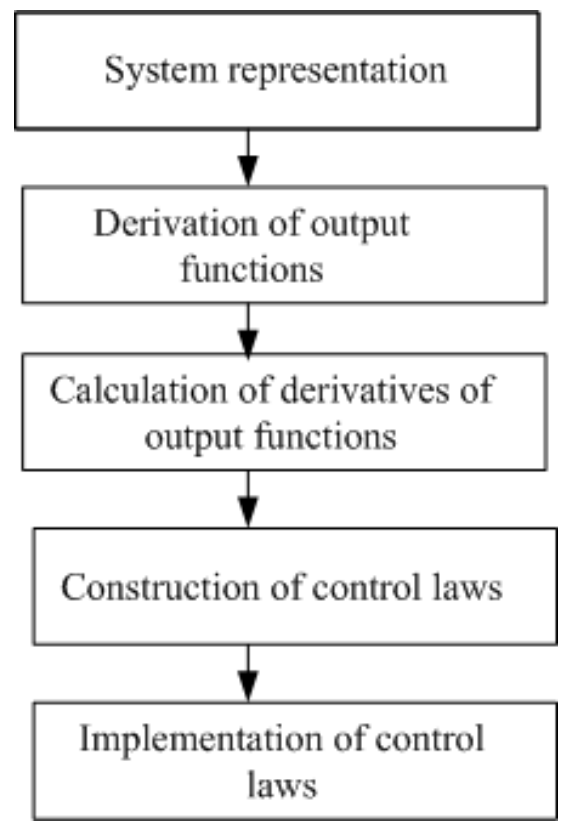

Fig. 1: Excitation control system framework

\section{I Power System Description}

The power system model used for this study is a third-order (flux-decay) model of a single machine connected to an infinite bus. It is represented by [57-59]

$$
\begin{aligned}
& \frac{\mathrm{d} \delta}{\mathrm{dt}}=\omega-\omega_{\mathrm{s}} \\
& \frac{\mathrm{d} \omega}{\mathrm{dt}}=\frac{\mathrm{T}_{\mathrm{m}}}{\mathrm{M}}-\frac{\mathrm{D}}{\mathrm{M}}\left(\omega-\omega_{\mathrm{S}}\right)+\left(\frac{1}{\mathrm{X}_{\mathrm{d}}^{\prime}+\mathrm{X}_{\mathrm{E}}}-\frac{1}{\mathrm{X}_{\mathrm{q}}+\mathrm{X}_{\mathrm{E}}}\right) \frac{1}{\mathrm{M}} \frac{\mathrm{V}^{2}}{2} \sin 2 \delta \\
& -\left(\frac{1}{\mathrm{x}_{\mathrm{d}}^{\prime}+\mathrm{X}_{\mathrm{E}}}\right) \frac{1}{\mathrm{M}} \mathrm{VE}_{\mathrm{q}}^{\prime} \sin \delta \\
& \frac{\mathrm{dE}_{\mathrm{q}}^{\prime}}{\mathrm{dt}}=-\frac{\left(\mathrm{X}_{\mathrm{d}}+\mathrm{X}_{\mathrm{E}}\right)}{\mathrm{T}_{\mathrm{do}}^{\prime}\left(\mathrm{x}_{\mathrm{d}}^{\prime}+\mathrm{X}_{\mathrm{E}}\right)} \mathrm{E}_{\mathrm{q}}^{\prime}+\frac{\left(\mathrm{X}_{\mathrm{d}}-\mathrm{X}_{\mathrm{d}}^{\prime}\right)}{\mathrm{T}_{\mathrm{do}}^{\prime}\left(\mathrm{X}_{\mathrm{d}}^{\prime}+\mathrm{X}_{\mathrm{E}}\right)} \mathrm{V} \cos \delta+\frac{1}{\mathrm{~T}_{\mathrm{do}}^{\prime}} \mathrm{E}_{\mathrm{f}}
\end{aligned}
$$

where $\delta$ is the rotor or torque angle in radians, $\omega$ is the rotor speed in radians/s, $E_{q}^{\prime}$ is the q-axis voltage which is proportional to the field winding flux linkage, $\mathrm{T}_{\mathrm{m}}$ is the input torque, $\mathrm{M}=2 \mathrm{H} / \omega_{\mathrm{s}}$, is the moment of inertia, with $\mathrm{H}$ being the generator inertia constant in seconds, D is the damping constant, $\omega_{\mathrm{s}}$ is the synchronous speed of the generator, $\mathrm{V}$ is the magnitude of the voltage of the infinite bus, and $E_{\mathrm{f}}$ represents the excitation coil voltage. Further, $\mathrm{x}_{\mathrm{E}}$ is the transmission line reactance, $x_{d}$ and $x_{q}$ are synchronous reactances, $x_{d}^{\prime}$ and $x_{q}^{\prime}$ are transient reactances, and $\mathrm{T}_{\mathrm{do}}^{\prime}$ and $\mathrm{T}_{\mathrm{qo}}^{\prime}$ are open-circuit transient time constants. The values of the model parameters are given in Appendix I.

The equilibrium point of the model given in equations (1), (2), and (3) is

$$
\left(\delta_{0}, \omega_{0}, \mathrm{E}_{\mathrm{q} 0}^{\prime}\right)=(0.6768,314.29,1.1300) .
$$

\section{II.II Determination of the Power System Output Function}

The system output function is chosen such that the system relative degree with respect to the function is equal to the order of the system. This condition of equality is often sought in order to arrive at an exactly linearizable model (through a nonlinear state feedback controller) of the system. In a broad term, the relative degree of any nonlinear system is the number of times its output function will be time-differentiated to yield most immediately an expression which is a function of the control signal. Instead of calculating the relative degree directly, an algorithm [60] for checking whether the order of a dynamic system is the same as its relative degree can be employed. This algorithm states that the relative degree, $r$, of a nonlinear single-input single-output system

$$
\dot{\mathrm{x}}=\mathrm{f}(\mathrm{x})+\mathrm{g}(\mathrm{x}) \mathrm{u}
$$

where $\mathrm{x} \in \mathbb{R}^{n}, \mathrm{f}(\mathrm{x}) \in \mathbb{R}^{n}, \mathrm{~g}(\mathrm{x}) \in \mathbb{R}^{n}$, and $\mathrm{u}$ is the control input, equals the order, $n$, of the system if and only if:

i) the rank of the matrix $\mathrm{M}=$ 
$\left[\mathrm{g}(\mathrm{x}) \quad \operatorname{ad}_{\mathrm{f}} \mathrm{g}(\mathrm{x}) \quad \operatorname{ad}_{\mathrm{f}}^{2} \mathrm{~g}(x) \quad \cdots \quad \operatorname{ad}_{\mathrm{f}}^{\mathrm{n}-1} \mathrm{~g}(\mathrm{x})\right]$ at the system operating point is $\mathrm{n}$; and

ii) the rank of each of the matrices $\mathrm{N}=$

$\left[\mathrm{g}(\mathrm{x}) \quad \operatorname{ad}_{\mathrm{f}} \mathrm{g}(\mathrm{x}) \quad \operatorname{ad}_{\mathrm{f}}^{2} \mathrm{~g}(\mathrm{x}) \quad \cdots \quad \operatorname{ad}_{\mathrm{f}}^{\mathrm{n}-2} \mathrm{~g}(\mathrm{x})\right]$ and $\mathrm{N}_{\mathrm{v}}=$ $\left[\begin{array}{lllll}\mathrm{g}(\mathrm{x}) & \operatorname{ad}_{\mathrm{f}} \mathrm{g}(\mathrm{x}) & \cdots & \operatorname{ad}_{\mathrm{f}}^{\mathrm{n}-2} \mathrm{~g}(\mathrm{x}) & {\left[\operatorname{ad}_{\mathrm{f}}^{\mathrm{j}} \mathrm{g}(\mathrm{x}), \operatorname{ad}_{\mathrm{f}}^{\mathrm{k}} \mathrm{g}(\mathrm{x})\right.}\end{array}\right]$ is $n-2$.

$\mathrm{j}=\mathrm{k}=0,1,2, \ldots, \mathrm{n}-2 ; \mathrm{j} \neq \mathrm{k} ; \operatorname{ad}_{\mathrm{f}}^{\mathrm{i}} \mathrm{g}(x)=$ $\operatorname{ad}_{\mathrm{f}}\left(\operatorname{ad}_{\mathrm{f}}^{\mathrm{i}-1} \mathrm{~g}(\mathrm{x})\right)$; and $\operatorname{ad}_{\mathrm{f}} \mathrm{g}(\mathrm{x})$ is the Lie bracket of $\mathrm{g}(\mathrm{x})$ along $\mathrm{f}(\mathrm{x})$.

Application of this algorithm to the system model given in equations (1), (2), and (3) show that the system output function exists (see Appendix II for this application). The next step is to find the output function. Using the general algorithm given in Appendix III, the output function that leads to the system relative degree $r=3$ is the rotor angle deviation

$$
\delta_{\Delta}=\delta-\delta_{0},
$$

where $\delta_{0}$ is the equilibrium value of the rotor angle.

\section{II.III Determination of System Control Signals}

\section{II.III.I Control Law 1}

This is a discontinuous feedback control law which ensures that the output function and its derivatives converge in finite time. It is expressed as

$$
\mathrm{u}_{\mathrm{L} 1}=-\alpha \operatorname{sat}\left(\beta_{\mathrm{n}-1}, \mathrm{c}_{\mathrm{n}-1}\right)=-\alpha \operatorname{sat}\left(\beta_{2}, \mathrm{c}_{2}\right),
$$

where

$$
\begin{aligned}
& \beta_{2}=\frac{\ddot{\delta}_{\Delta} \mathrm{k}_{2} \gamma_{2} \operatorname{sat}\left(\beta_{1}, \mathrm{c}_{1}\right)}{\gamma_{3}} \\
& \beta_{1}=\frac{\dot{\delta}_{\Delta} \mathrm{k}_{1} \gamma_{1} \operatorname{sat}\left(\beta_{0}, \mathrm{c}_{0}\right)}{\gamma_{3}} \\
& \beta_{0}=\frac{\delta_{\Delta}}{\left|\delta_{\Delta}\right|} \\
& \gamma_{\mathrm{i}}=\left(\left|\delta_{\Delta}\right|^{(\mathrm{n}-1) !}+\left|\dot{\delta}_{\Delta}\right|^{\mathrm{n}(\mathrm{n}-2) !}+\cdots+\right. \\
& \left.\left|\delta_{\Delta}^{(i-1)}\right|^{\frac{(n) !}{(n+1-i)}}\right)^{\frac{n-i}{n !}} \\
& \mathrm{i}=1,2, \cdots, \mathrm{n}-1 \\
& \gamma_{\mathrm{n}}=\left(\left|\delta_{\Delta}\right|^{(\mathrm{n}-1) !}+\left|\dot{\delta}_{\Delta}\right|^{\mathrm{n}(\mathrm{n}-2) !}+\cdots+\right. \\
& \left.\left|\delta_{\Delta}^{(n-1)}\right|^{n !}\right)^{\frac{1}{n !}}
\end{aligned}
$$

The expression in equation (7) is the modified form of the universal controller developed by Levant [61, 62]. The values of the controller parameters (i.e., $\alpha, \mathrm{k}_{1}, \mathrm{k}_{2}, \mathrm{c}_{0}, \mathrm{c}_{1}$, and $\mathrm{c}_{2}$ ) are obtained through simulation. The symbol sat(.) is the saturation function shown in Fig. 2.

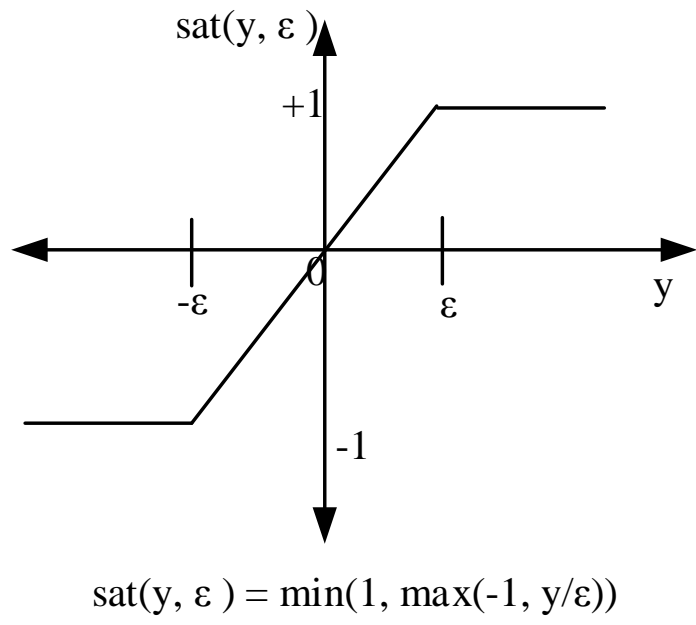

Fig. 2: Graphical representation of a saturation function

\section{II.III.II Control Law II}

This control law is based on the concept of exact feedback linearization and state homogeneity. First, the nonlinear model in equations (1), (2), and (3) is transformed into the form

$\frac{\mathrm{dq}_{1}}{\mathrm{dt}}=\mathrm{q}_{2}$

$\frac{\mathrm{dq}_{2}}{\mathrm{dt}}=\mathrm{q}_{3}$

$\frac{\mathrm{dq}_{3}}{\mathrm{dt}}=\mathrm{v}$.

The new variables are defined as

$$
\begin{aligned}
& \mathrm{q}_{1}=\delta_{\Delta} \\
& \mathrm{q}_{2}=\mathrm{L}_{\mathrm{f}} \delta_{\Delta} \\
& \mathrm{q}_{3}=\mathrm{L}_{\mathrm{f}}^{2} \delta_{\Delta} \\
& \mathrm{v}=\mathrm{L}_{\mathrm{f}}^{3} \delta_{\Delta}+\mathrm{L}_{\mathrm{g}} \mathrm{L}_{\mathrm{f}}^{2} \delta_{\Delta} \mathrm{E}_{\mathrm{f}} .
\end{aligned}
$$

The symbol $\mathrm{L}_{\mathrm{f}} \delta_{\Delta}$ is called the Lie derivative of $\delta_{\Delta}$ along $\mathrm{f}(\mathrm{x})$. From equation (14), the control input $\mathrm{u}_{\mathrm{L} 2}$ is

$\mathrm{u}_{\mathrm{L} 2}=\frac{v-\mathrm{L}_{\mathrm{f}}^{3} \delta_{\Delta}}{\mathrm{Lg}_{\mathrm{f}}^{2} \delta_{\Delta}}$

The next step is to find $\mathrm{v}$. Based on the transformed model in equations (8), (9), and (10), the expression for $\mathrm{v}$ is given as

$\mathrm{v}=-\left[\alpha_{1} \operatorname{sat}\left(\mathrm{q}_{1}, \mathrm{c}_{1}\right)+\alpha_{2} \operatorname{sat}\left(\mathrm{q}_{2}, \mathrm{c}_{2}\right)+\alpha_{3} \operatorname{sat}\left(\mathrm{q}_{3}, \mathrm{c}_{3}\right)\right]$, 
where $\alpha_{1}, \alpha_{2}$, and $\alpha_{3}$ are chosen [63] such that the characteristic equation

$$
s^{3}+\alpha_{3} s^{2}+\alpha_{2} s+\alpha_{1}=0
$$

is stable; $\mathrm{c}_{1}, \mathrm{c}_{2}$, and $\mathrm{c}_{3}$ are positive constants.

\section{II.III.III Control Law III}

This is a variant of the discontinuous feedback control law in equation (7), and it is adopted to reduce the complexity of $\mathrm{u}_{\mathrm{L} 1}$ and provide better performance in terms of robustness. It is expressed as

$$
\mathrm{u}_{\mathrm{L} 3}=-\alpha \operatorname{sat}\left(\psi_{\mathrm{n}-1}, \mathrm{c}\right)=-\alpha \operatorname{sat}\left(\psi_{2}, \mathrm{c}\right),
$$

where

$$
\begin{aligned}
& \psi_{2}=\ddot{\delta}_{\Delta} \mathrm{k}_{2} \gamma_{2} \operatorname{sat}\left(\psi_{1}, \mathrm{c}\right) \\
& \psi_{1}=\dot{\delta}_{\Delta} \mathrm{k}_{1} \gamma_{1} \operatorname{sign}\left(\psi_{0}\right) \\
& \psi_{0}=\delta_{\Delta}
\end{aligned}
$$

and $\gamma_{\mathrm{i}}, \mathrm{i}=1,2, \mathrm{n}-1$, are as defined previously. Similarly, the values of the controller parameters $\alpha, \mathrm{k}_{1}, \mathrm{k}_{2}$, and $\mathrm{c}$ are obtained through simulation. The symbol sign(.) is the "signum" function shown in Fig. 3.

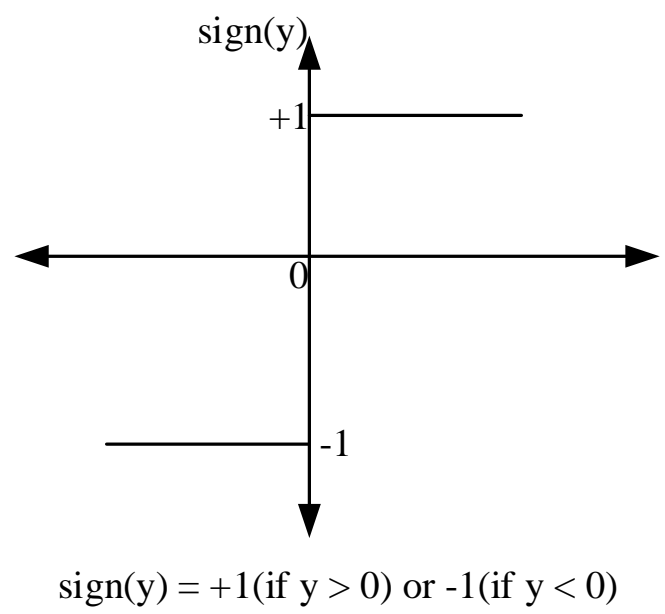

Fig. 3: Graphical representation of a signum function

\section{RESULTS AND DISCUSSION}

To evaluate the performance of the three control laws, the model system (SMIB) is subjected to a three-phase fault at the infinite bus. Three fault clearance times are considered: 9, 14.5, and 14.7 cycles.

\section{I Fault at Infinite Bus with Fault Clearance Time of}

\section{Cycles}

Fig. 4(a), Fig. 4(b), and Fig. 4(c) present respectively the waveforms of synchronous generator rotor angle, rotor speed, and quadrature axis induced EMF when the model system is subjected to a three-phase fault at an infinite bus, with fault duration of 9 cycles. It can be observed that the load angles and rotor speeds obtained due to these three control laws and the open-loop system have a similar first peak, with CL2 exhibiting better performance from a power oscillation point of view, followed by CL3. Fig. 4(c) shows that the improved performance of CL2 is achieved with minimum adjustment of $\mathrm{E}_{\mathrm{q}}^{\prime}$ (adjustment needed in the generator EMF through manipulation of the excitation system to counter the demagnetization effect of the armature reaction during a fault).

\section{III.II Fault at Infinite Bus with Fault Clearance Time of 14.5 Cycles}

This section repeats the case in Section III.I, but for fault clearance time of 14.5 cycles. It is clear that the open-loop case has lost synchronism, while the model system under the control action of CL1, CL2 and CL3 remains operational, with CL3 exhibiting better damping in load angle, but higher first peak than CL2 (see Fig. 5(a)). Fig. 5(b) shows that the rotor speeds for the open-loop and those for CL1, CL2 and CL3 have similar peaks, despite that the open-loop case has fallen out of the slip. Fig. 5(c) indicates that the quadrature axis EMF for the openloop case has collapsed, while those for CL1, CL2 and CL3 regain their previous steady-state equilibrium points.

\section{III.III Fault at Infinite Bus with Fault Clearance Time of 14.7 Cycles}

In order to determine the control law with the greatest robustness ability, the case in Section III. I is repeated, but this time for fault clearance time of 14.7 cycles. Note that the cases for the open-loop and CL1 have lost their synchronisms, while the system, under the action of CL2 and CL3, remains operational, with CL2 exhibiting lower first peak and faster deceleration compared to CL3 (see Fig. 6(a)). The plots for the rotor speeds in Fig. 6(b) support the observations drawn from the results in Fig. 6(a). Fig. 6(c) indicates that the quadrature axis EMF for the open-loop and CL1 cases have collapsed, while those for CL2 and CL3 regain their previous steady-state equilibrium points. 


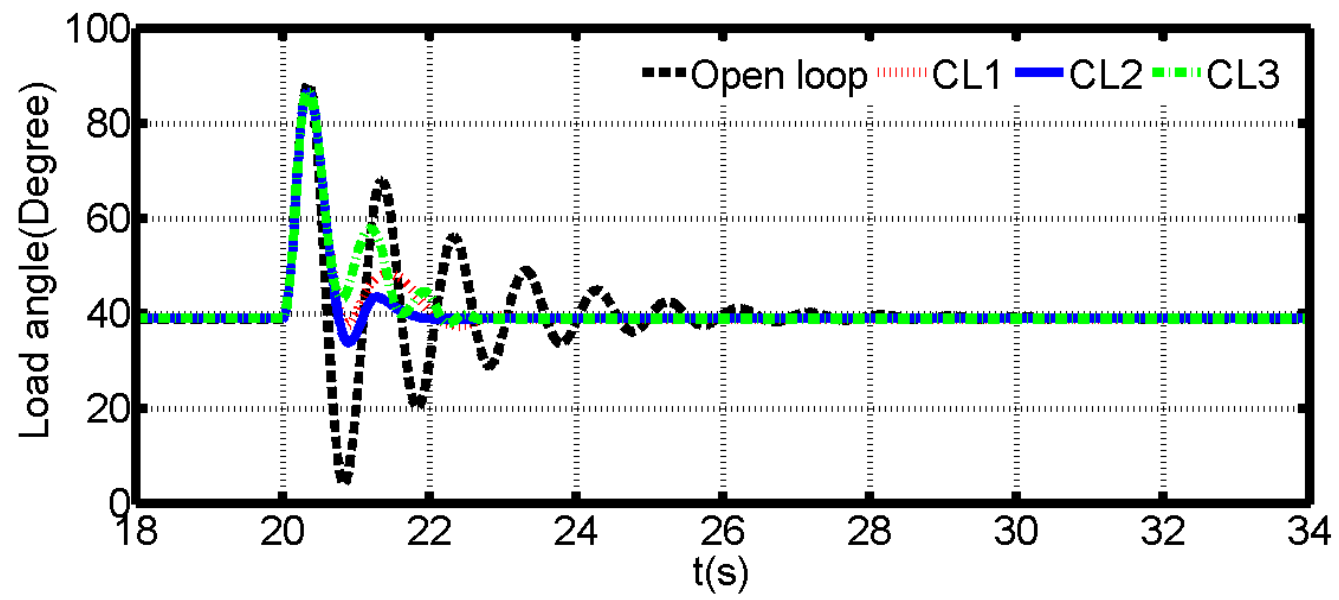

(a) Load angle

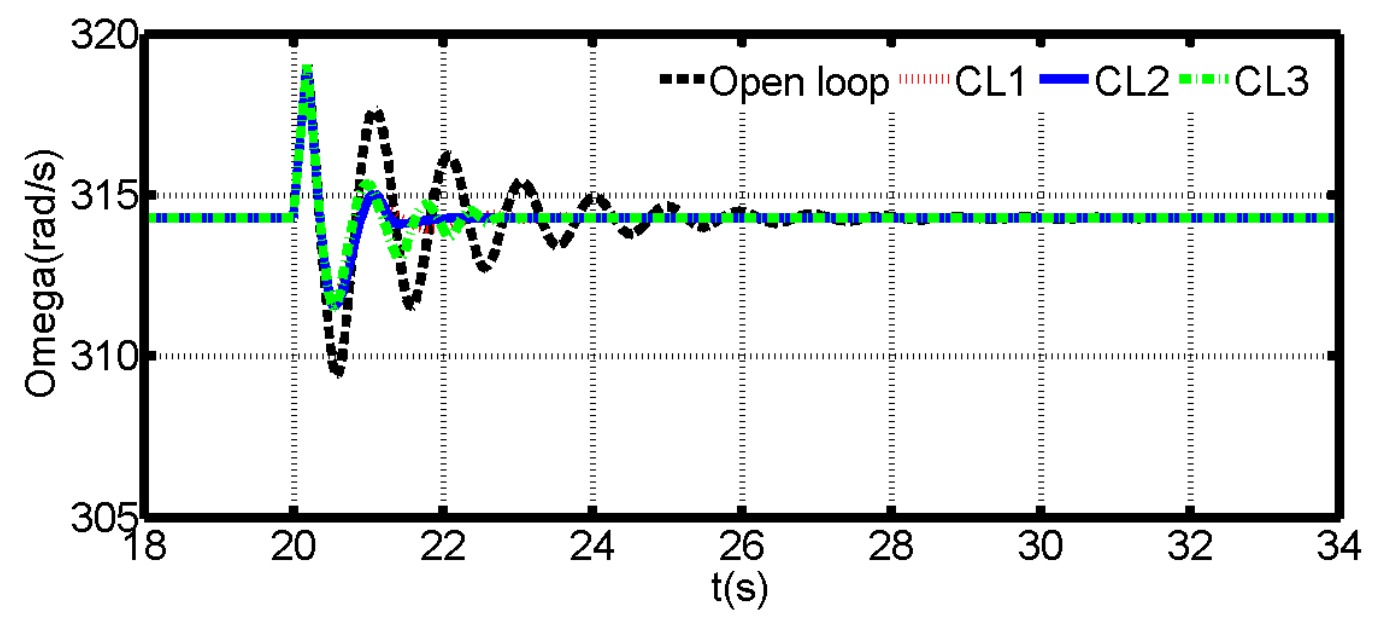

(b) Rotor speed

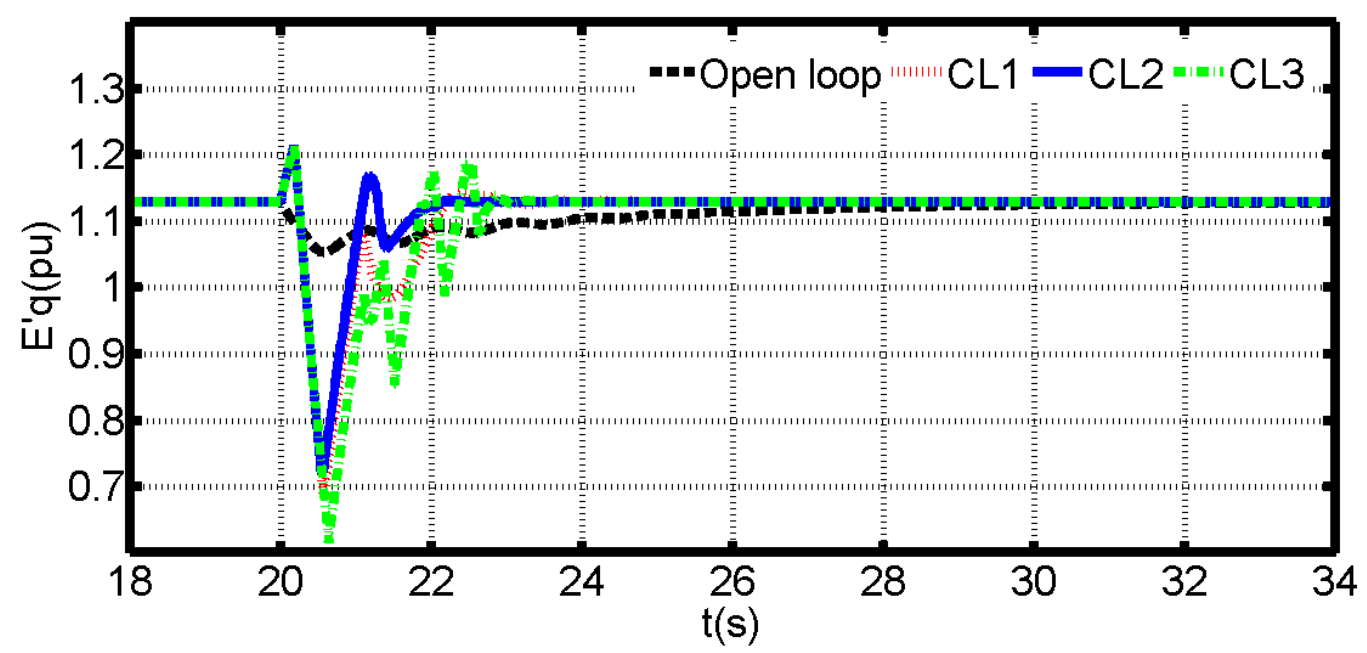

(c) Quadrature EMF (E’q)

Fig. 4: System waveforms comparing the performances of control laws (CL1, CL2 and CL3) for an infinite bus fault cleared after 9 cycles 


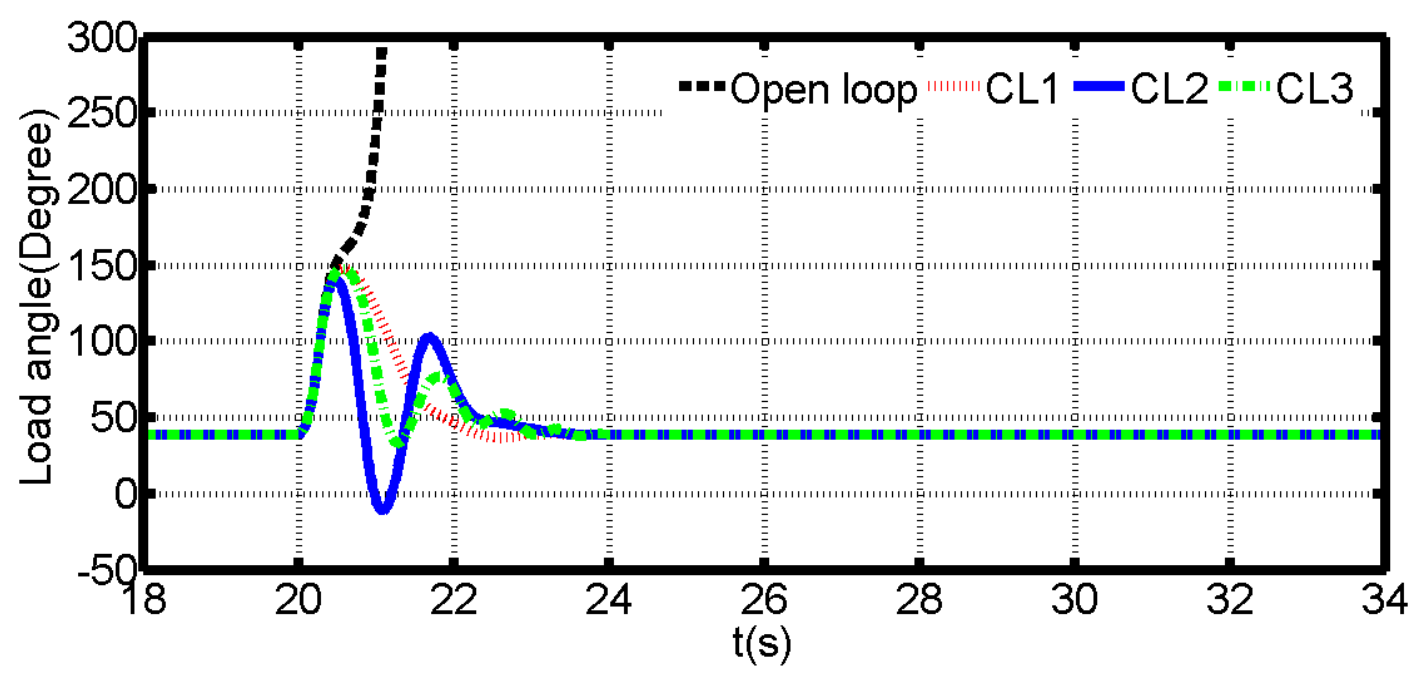

(a) Load angle

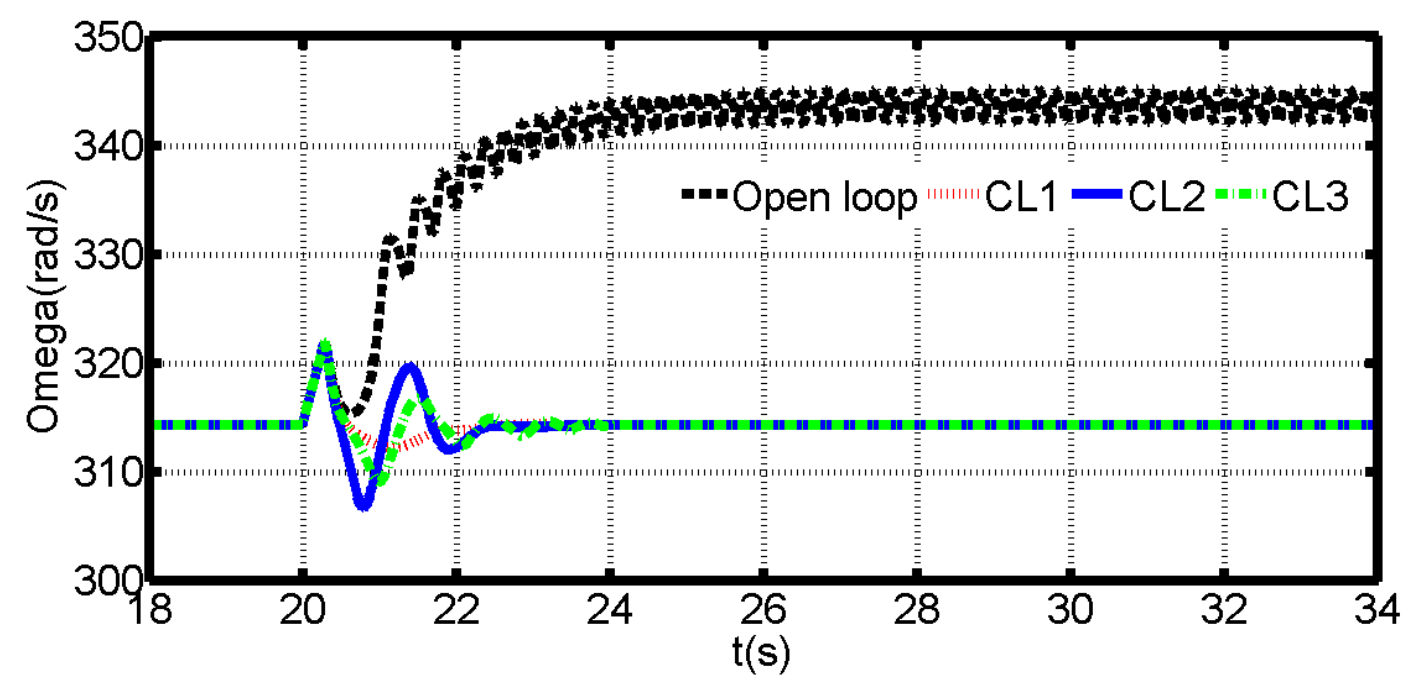

(b) Rotor speed

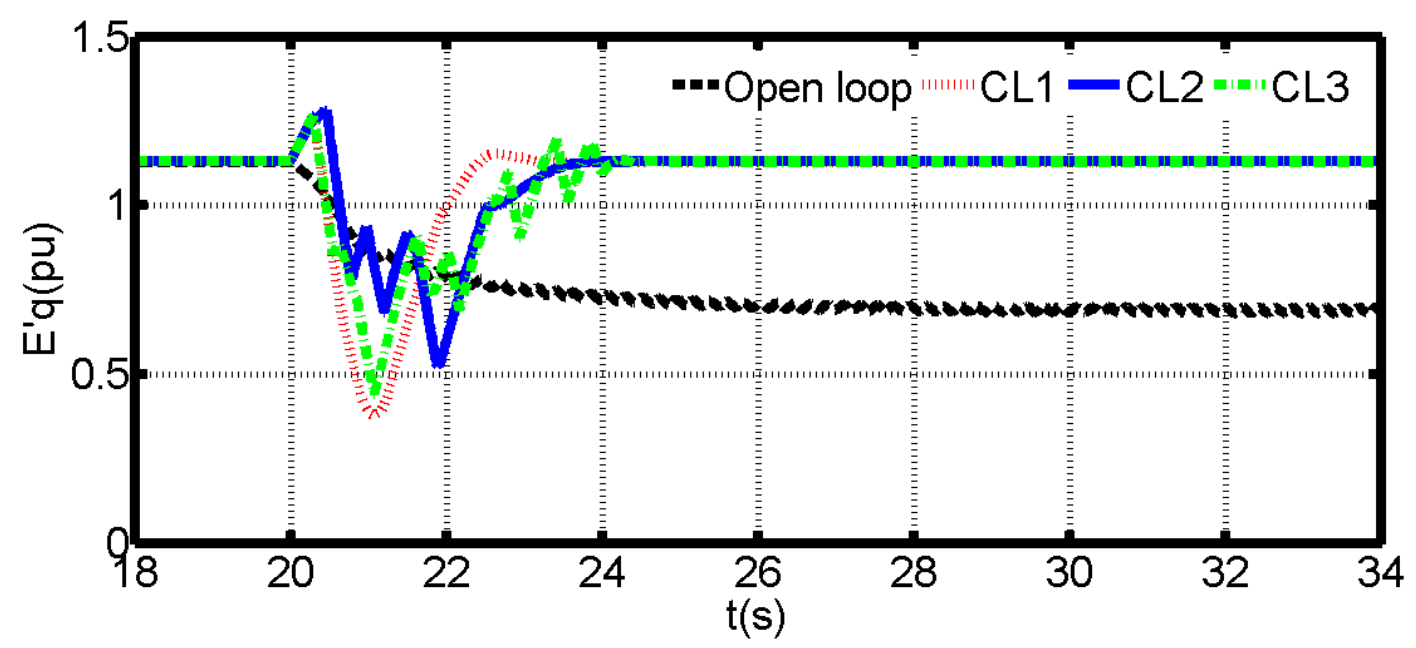

(c) Quadrature EMF ( $\left.\mathrm{E}_{\mathrm{q}}^{\prime}\right)$

Fig. 5: System waveforms comparing the performances of control laws (CL1, CL2 and CL3) for an infinite bus fault cleared after 14.5 cycles 


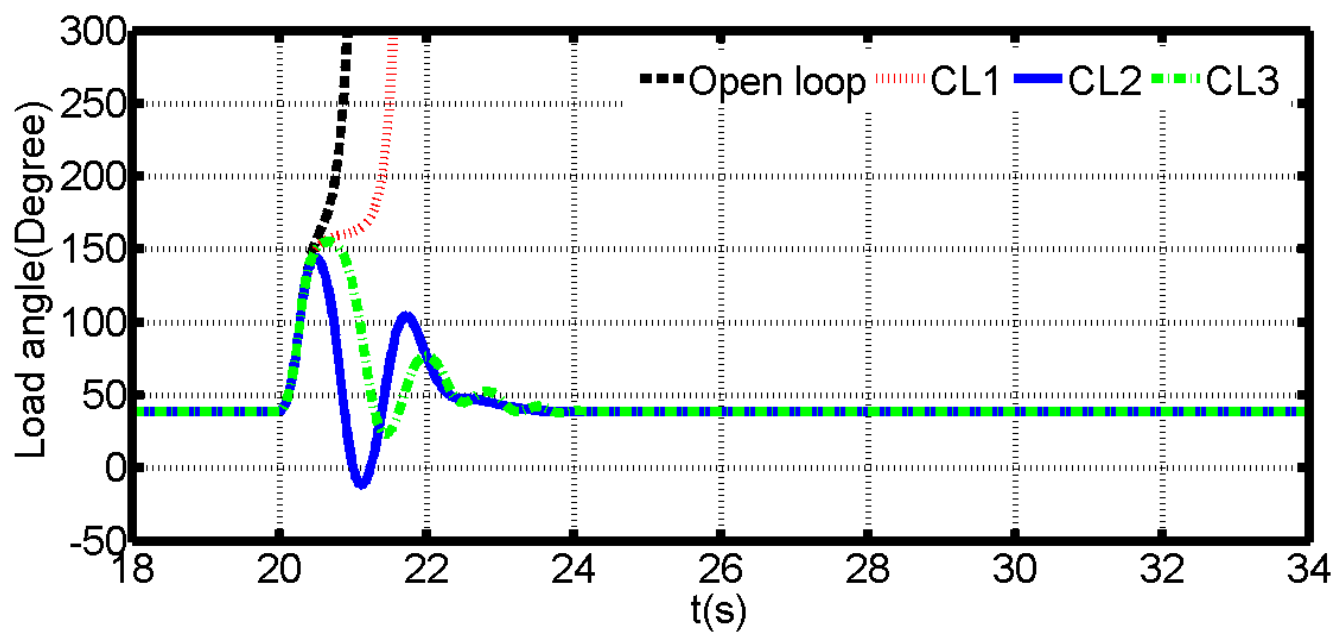

(a) Load angle

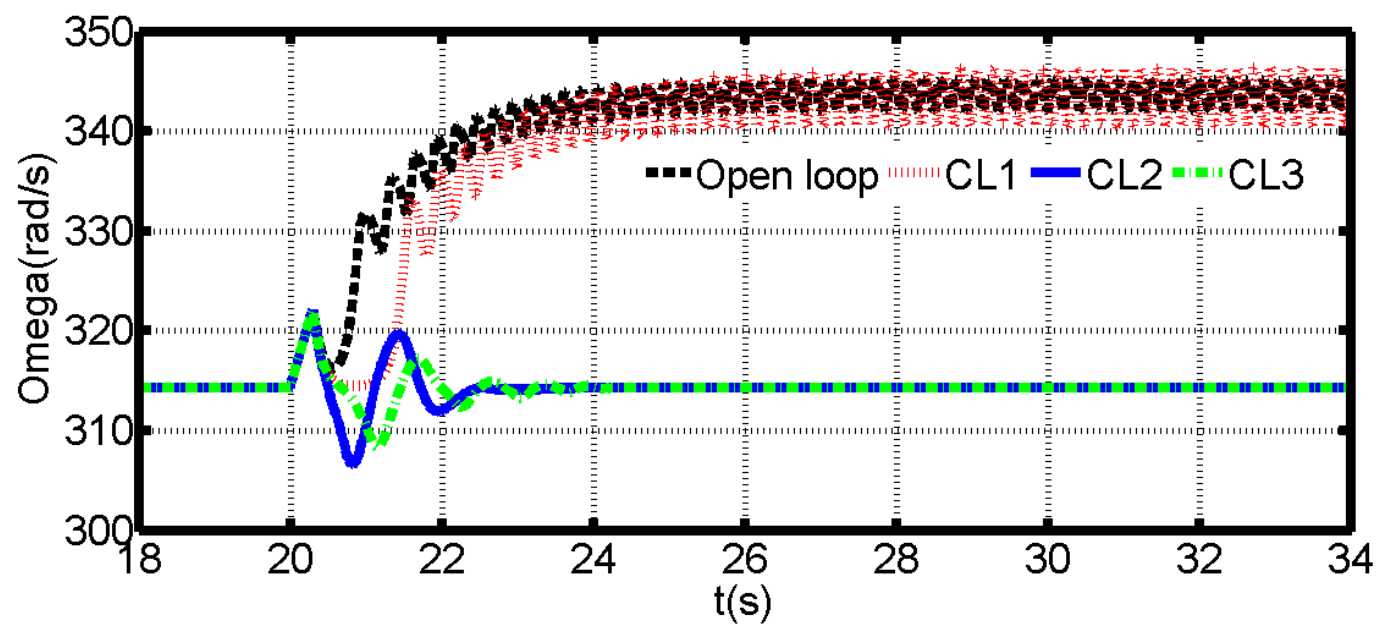

(b) Rotor speed

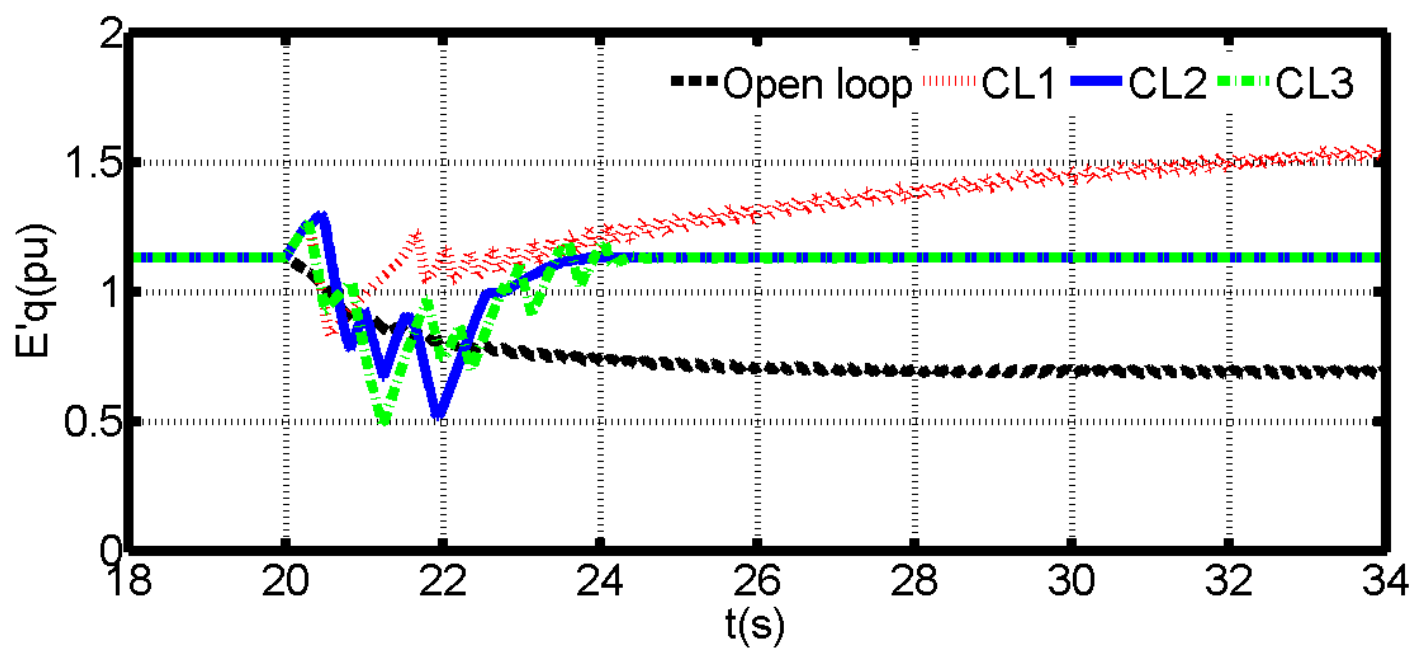

(c) Quadrature EMF (E'q)

Fig. 6: System waveforms comparing the performances of control laws (CL1, CL2 and CL3) for an infinite bus fault cleared after 14.7 cycles 


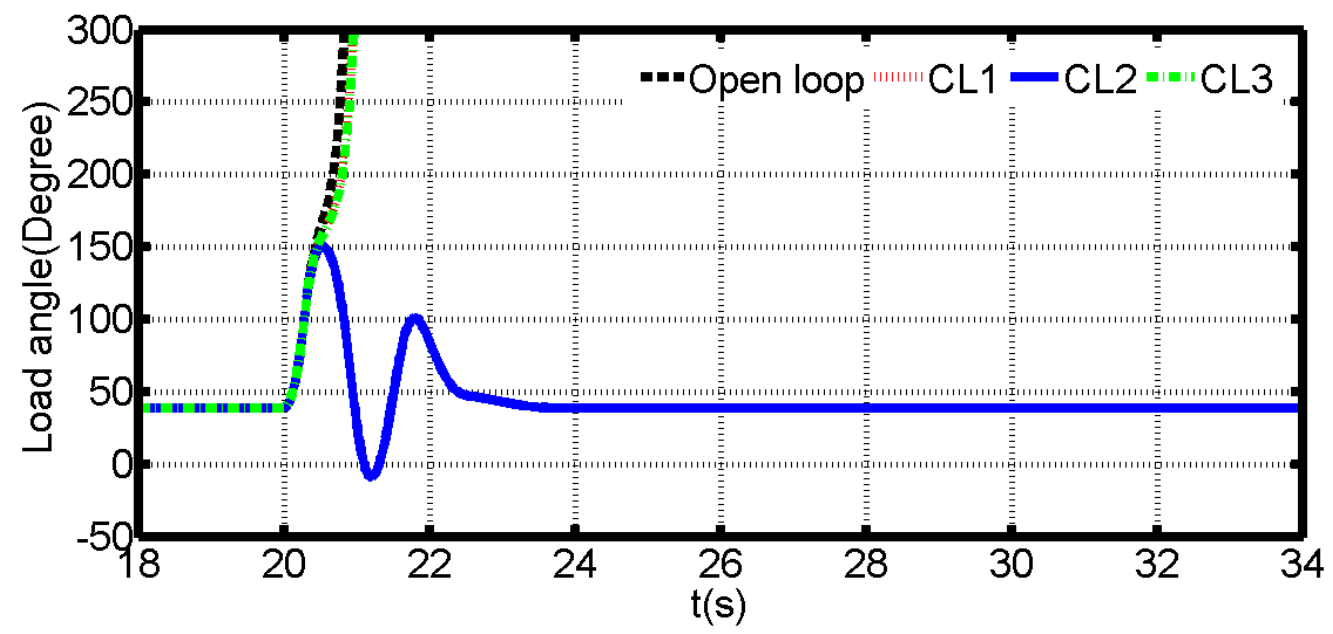

(a) Load angle

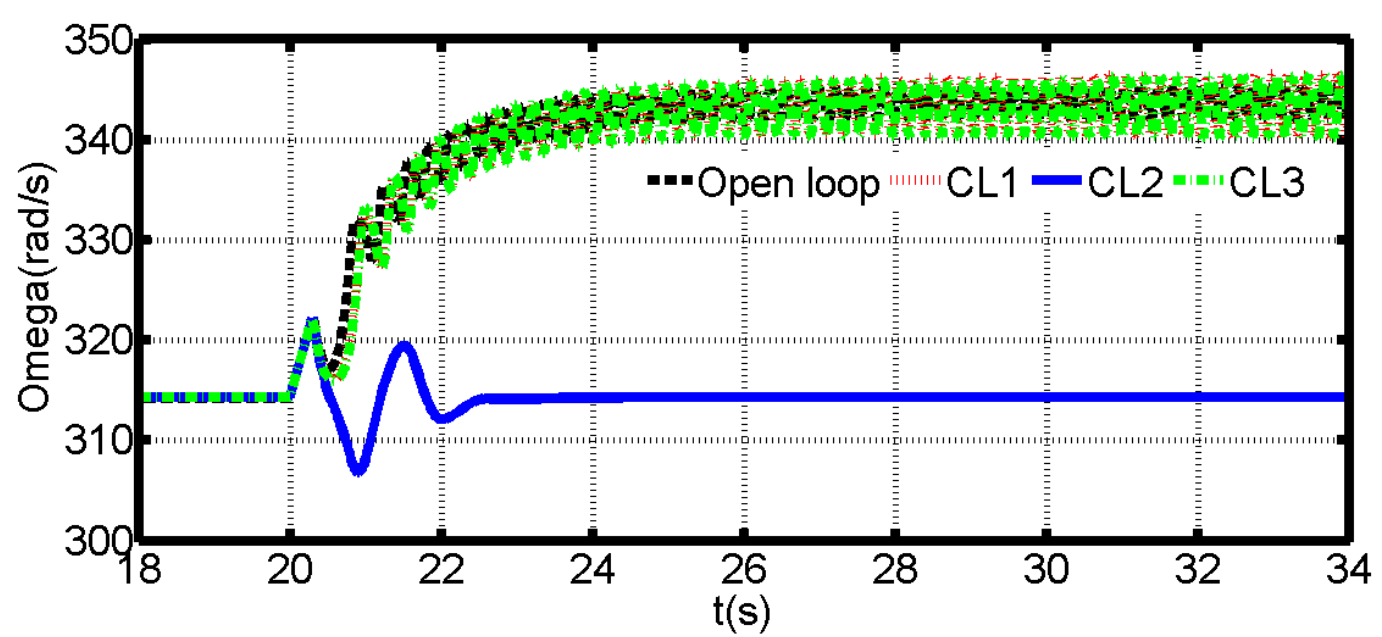

(b) Rotor speed

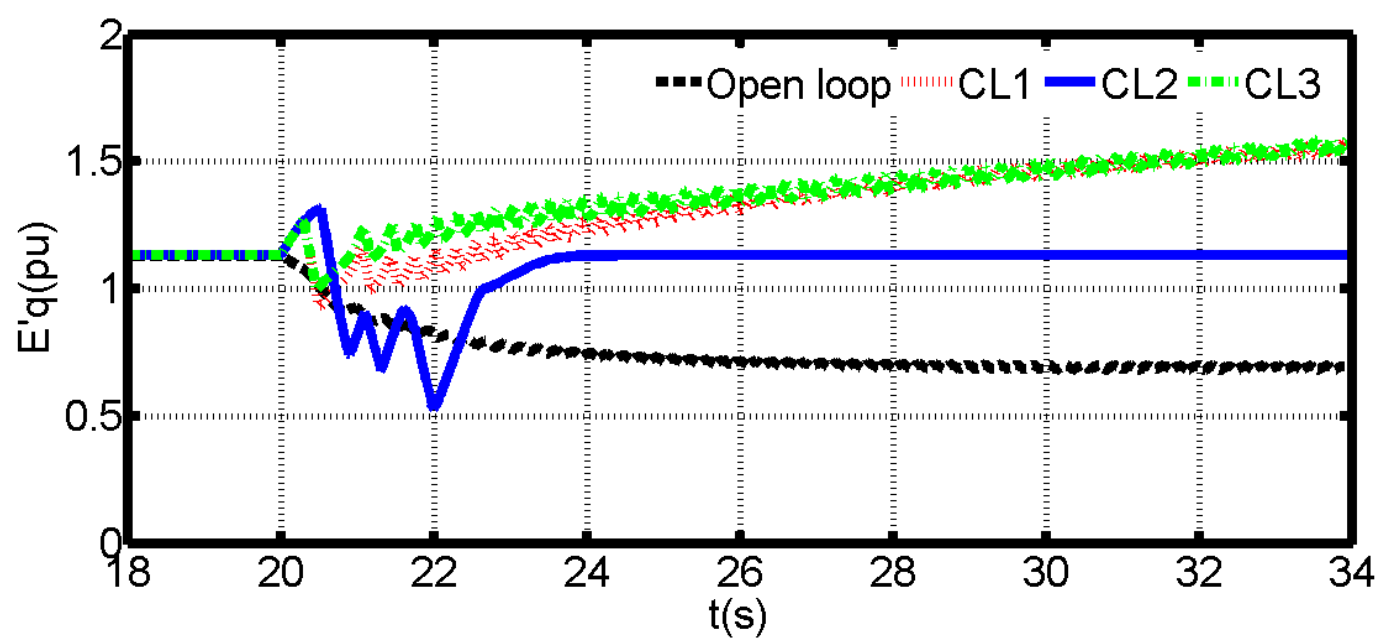

(c) Quadrature EMF (E' $\left.{ }_{q}\right)$

Fig. 7: System waveforms comparing the performances of control laws (CL1, CL2 and CL3) for an infinite bus fault cleared after 15 cycles 


\section{III.IV Fault at Infinite Bus with Fault Clearance Time of 15 Cycles}

Following on from the case in Section III.III, with the fault clearance time increased to 15 cycles, it is clear from Fig. 7 that the cases for the open-loop, CL1, and CL3 have lost their synchronisms, while the model system still remains operational under CL2. Therefore, it can be concluded that the control law CL2 performs better than CL1 and CL3 in extending the critical clearance time of a single machine connected to an infinite bus system being studied. After further simulation, it is discovered that the system (under CL2) can withstand fault for a maximum duration of 15.30 cycles.

\section{CONCLUSION}

Three nonlinear excitation controllers have been presented in this paper, with their performance characteristics investigated by simulation using a model power system represented by a single machine connected to an infinite bus. The second controller (CL2), which is an improved version of the general homogeneity-based controller, performs better in terms of the ability to withstand fault cycles than the other two (CL1 and CL3), which are modified versions of universal sliding mode controllers. These controllers can be realized using fast power semiconductor devices.

\section{ACKNOWLEDGEMENTS}

The management of Covenant University is acknowledged for their part sponsorship and support toward the success of this research.

This work is principally based on the research supported in part by the National Research Foundation of South Africa (Unique Grant No. 107541), Department of Higher Education and Training Research Department Grant (DHET-RDG), and Centre for Energy and Electric Power, Tshwane University of Technology (TUT), South Africa.

\section{APPENDIX I}

The parameter values of the system model defined in equation (1), (2), and (3) are [57, 64, 65]: $X_{d}=0.9$ p.u.; $X_{q}=0.7$ p.u.; $\mathrm{X}_{\mathrm{d}}{ }_{\mathrm{d}}=0.2$ p.u.; $\mathrm{X}_{\mathrm{q}}{ }=0.2$ p.u.; $\mathrm{T}^{\prime}{ }_{\mathrm{do}}=5.00 \mathrm{~s} ; \mathrm{T}_{\text {qo }}=0.13 \mathrm{~s} ; \mathrm{H}=$ $5.00 \mathrm{~s} ; \mathrm{T}_{\mathrm{m}}=0.8413 ; \mathrm{X}_{\mathrm{E}}=0.24$ p.u.; $\mathrm{X}_{\mathrm{T}}=0.13$ p.u.; $\mathrm{V}=1.0$ p.u.

Let $\left(x_{10}, x_{20}, x_{30}\right)$ represent the equilibrium point of the model, which is rewritten as

$$
\dot{\mathrm{x}}=\mathrm{f}(\mathrm{x})+\mathrm{g}(\mathrm{x}) \mathrm{u}
$$

where

$$
f(x)=\left(\begin{array}{c}
x_{2}-\omega_{s} \\
\left.A_{1}+\frac{1}{2} A_{2} V^{2} \sin 2 x_{1}-A_{3} V x_{3} \sin x_{1}-\frac{D}{M}\left(x_{2}-\omega_{s}\right)\right) \\
-B_{1} x_{3}+B_{2} V \cos x_{1}
\end{array}\right)
$$

$$
\begin{aligned}
& \mathrm{g}(\mathrm{x})=\left(\begin{array}{c}
0 \\
0 \\
\frac{1}{T_{d o}^{\prime}}
\end{array}\right) \\
& \mathrm{A}_{1}=\frac{\mathrm{T}_{\mathrm{m}}}{\mathrm{M}} \\
& \mathrm{A}_{2}=\frac{1}{\mathrm{M}}\left(\frac{1}{\mathrm{x}_{\mathrm{d}}^{\prime}+\mathrm{X}_{\mathrm{E}}}-\frac{1}{\mathrm{X}_{\mathrm{q}}+\mathrm{X}_{\mathrm{E}}}\right) \\
& \mathrm{A}_{3}=\left(\frac{1}{\mathrm{X}_{\mathrm{d}}^{\prime}+\mathrm{X}_{\mathrm{E}}}\right) \frac{1}{\mathrm{M}} \\
& \mathrm{B}_{1}=\frac{\left(\mathrm{X}_{\mathrm{d}}+\mathrm{X}_{\mathrm{E}}\right)}{\mathrm{T}_{\mathrm{do}}^{\prime}\left(\mathrm{X}_{\mathrm{d}}^{\prime}+\mathrm{X}_{\mathrm{E}}\right)} \\
& \mathrm{B}_{2}=\frac{\left(\mathrm{X}_{\mathrm{d}}-\mathrm{X}_{\mathrm{d}}^{\prime}\right)}{\mathrm{T}_{\mathrm{do}}^{\prime}\left(\mathrm{X}_{\mathrm{d}}^{\prime}+\mathrm{X}_{\mathrm{E}}\right)}
\end{aligned}
$$

At equilibrium, all derivative terms in equation (AI.1) are set to zero, i.e.,

$$
\begin{aligned}
& x_{20}-\omega_{\mathrm{s}}=0 \\
& \mathrm{~A}_{1}+\frac{1}{2} \mathrm{~A}_{2} \mathrm{~V}^{2} \sin 2 x_{10}-\mathrm{A}_{3} \mathrm{~V} x_{30} \sin x_{10}=0 \\
& -\mathrm{B}_{1} x_{30}+\mathrm{B}_{2} \mathrm{~V} \cos x_{10}+\frac{1}{\mathrm{~T}_{\mathrm{do}}^{\prime}} \mathrm{u}_{0}=0
\end{aligned}
$$

Therefore,

$$
x_{20}=\omega_{\mathrm{s}}
$$

$$
\begin{aligned}
& x_{30}=\frac{\mathrm{A}_{1}+\frac{1}{2} \mathrm{~A}_{2} \mathrm{~V}^{2} \sin 2 x_{10}}{\mathrm{~A}_{3} \mathrm{~V} \sin x_{10}} \\
& x_{30}=\frac{\mathrm{B}_{2} \mathrm{~V} \cos x_{10}+\frac{1}{\mathrm{~T}_{\mathrm{do}}^{\prime}} \mathrm{u}_{0}}{\mathrm{~B}_{1}}
\end{aligned}
$$

Combining equations (AI.3) and (AI.4), and using the identity $\sin x_{10} \cos x_{10} \equiv \frac{1}{2} \sin 2 x_{10}$, gives

$$
\left(\frac{1}{2} \mathrm{~B}_{2} \mathrm{~V}^{2} \mathrm{~A}_{3}-\frac{1}{2} \mathrm{~B}_{1} \mathrm{~V}^{2} \mathrm{~A}_{2}\right) \sin 2 x_{10}+\frac{1}{\mathrm{~T}_{\mathrm{do}}^{\prime}} \mathrm{A}_{3} \mathrm{Vu}_{0} \sin x_{10}=
$$
$\mathrm{A}_{1} \mathrm{~B}_{1}$ (AI.5)

To obtain $x_{10}$, equation (AI.5) is solved numerically using MATLAB function "fsolve" as follows:

$\%$ This function file creates equation (AI.5).

function aweresult $=$ awefun $(x)$

system_parameters;

aweresult $=((B 2 * v * v * A 3 / 2)-$. .

$(B 1 * A 2 * v * v / 2)) * \sin (2 * x(1))+(A 3 * v / t d o p) * \sin (x(1))-A 1 * B 1$;

$\%$ End function

$\% \% \quad$ This script file solves equation (AI.5) by calling

$\% \%$ function file 'awefun'

options=optimset('Algorithm', 'Levenberg-Marquardt');

x_steadystate=fsolve( @awefun, x0,options)

$\% \% \quad$ End script 
And from either equation (AI.3) or (AI.4), $\mathrm{x}_{30}$ can be found. Hence,

$$
\left(\mathrm{x}_{10}, \mathrm{x}_{20}, \mathrm{x}_{30}\right)=\left(\delta_{0}, \omega_{0}, \mathrm{E}_{\mathrm{q} 0}^{\prime}\right)=(0.6768,314.29,1.1300) \text {. }
$$

\section{APPENDIX II}

To confirm whether an output function that makes $r=n$ exists, the two conditions specified in Section 2.2 are tested as follows.

i) Compute the matrix $M=\left[\begin{array}{lll}g(x) & \operatorname{ad}_{f} g(x) & \operatorname{ad}_{f}^{2} g(x)\end{array}\right]$ and check its rank.

$$
\begin{aligned}
& g(x)=\left(\begin{array}{l}
g_{1} \\
g_{2} \\
g_{3}
\end{array}\right)=\left(\begin{array}{c}
0 \\
0 \\
1 / T_{d o}^{\prime}
\end{array}\right) \\
& \mathrm{f}(x)=\left(\begin{array}{l}
\mathrm{f}_{1} \\
\mathrm{f}_{2} \\
\mathrm{f}_{3}
\end{array}\right) \\
& =\left(\begin{array}{c}
x_{2}-\omega_{\mathrm{s}} \\
\mathrm{A}_{1}+\frac{1}{2} \mathrm{~A}_{2} \mathrm{~V}^{2} \sin 2 x_{1}-\mathrm{A}_{3} \mathrm{~V} x_{3} \sin x_{1}-\frac{\mathrm{D}}{\mathrm{M}}\left(x_{2}-\omega_{\mathrm{s}}\right) \\
-\mathrm{B}_{1} x_{3}+\mathrm{B}_{2} \mathrm{~V} \cos x_{1}
\end{array}\right) \\
& \operatorname{ad}_{\mathrm{f}} \mathrm{g}(\mathrm{x})=\frac{\partial \mathrm{g}}{\partial \mathrm{x}} \mathrm{f}(\mathrm{x})-\frac{\partial \mathrm{f}}{\partial \mathrm{x}} \mathrm{g}(\mathrm{x}) \\
& =0-\left[\begin{array}{ccc}
0 & 1 & 0 \\
\mathrm{~A}_{2} \mathrm{~V}^{2} \cos 2 x_{1}-\mathrm{A}_{3} \mathrm{~V} x_{3} \cos x_{1} & -\frac{\mathrm{D}}{\mathrm{M}} & -\mathrm{A}_{3} \mathrm{~V} \sin x_{1} \\
-\mathrm{B}_{2} \mathrm{~V} \sin x_{1} & 0 & -\mathrm{B}_{1}
\end{array}\right]\left(\begin{array}{l}
\mathrm{g}_{1} \\
\mathrm{~g}_{2} \\
\mathrm{~g}_{3}
\end{array}\right) \\
& =\left[\begin{array}{c}
0 \\
\frac{1}{T_{d o}^{\prime}} \mathrm{A}_{3} \mathrm{~V} \sin x_{1} \\
\frac{1}{T_{d o}^{\prime}} \mathrm{B}_{1}
\end{array}\right] \\
& \operatorname{ad}_{\mathrm{f}}^{2} \mathrm{~g}(x)=\frac{\partial\left(\operatorname{ad}_{\mathrm{f}} \mathrm{g}(\mathrm{x})\right)}{\partial \mathrm{x}} \mathrm{f}(\mathrm{x})-\frac{\partial \mathrm{f}}{\partial \mathrm{x}} \operatorname{ad}_{\mathrm{f}} \mathrm{g}(\mathrm{x}) \\
& =\left[\begin{array}{c}
\frac{1}{T_{d o}^{\prime}} \mathrm{A}_{3} \mathrm{~V} \sin x_{1} \\
\frac{x_{2}-\omega_{\mathrm{s}}}{T_{d o}^{\prime}} \mathrm{A}_{3} \mathrm{~V} \cos x_{1}+\frac{\mathrm{D}}{\mathrm{M} T_{d o}^{\prime}} \mathrm{A}_{3} \mathrm{~V} \sin x_{1}+\frac{1}{T_{d o}^{\prime}} \mathrm{B}_{1} \mathrm{~A}_{3} \mathrm{~V} \sin x_{1} \\
\frac{x_{2}-\omega_{\mathrm{s}}}{T_{d o}^{\prime}} \mathrm{B}_{1}+\frac{1}{T_{d o}^{\prime}} \mathrm{B}_{1}{ }^{2}
\end{array}\right]
\end{aligned}
$$

Thus,

$$
\mathrm{M}=\left[\begin{array}{ccc}
0 & 0 & \frac{1}{T_{d o}^{\prime}} \mathrm{A}_{3} \mathrm{~V} \sin x_{1} \\
0 & \frac{1}{T_{d o}^{\prime}} \mathrm{A}_{3} \mathrm{~V} \sin x_{1} & \frac{x_{2}-\omega_{s}}{T_{d o}^{\prime}} \mathrm{A}_{3} \mathrm{~V} \cos x_{1}+\frac{\mathrm{D}}{\mathrm{M} T_{d o}^{\prime}} \mathrm{A}_{3} \mathrm{~V} \sin x_{1}+\frac{1}{T_{d o}^{\prime}} \mathrm{B}_{1} \mathrm{~A}_{3} \mathrm{~V} \sin x_{1} \\
\frac{1}{T_{d o}^{\prime}} & \frac{1}{T_{d o}^{\prime}} \mathrm{B}_{1} & \frac{x_{2}-\omega_{s}}{T_{d o}^{\prime}} \mathrm{B}_{1}+\frac{1}{T_{d o}^{\prime}} \mathrm{B}_{1}{ }^{2}
\end{array}\right]
$$

Since the determinant of $\mathrm{M}$ is nonzero at the system operating point, i.e.,

$$
\mathrm{M} \neq-\frac{1}{{T_{d o}^{\prime}}^{3}} \mathrm{~A}_{3}^{2} \mathrm{~V}^{2} \sin ^{2} x_{10},
$$

then the rank of $M$ is 3. This condition is satisfied. ii) Determine the rank of the matrix $\mathrm{N}=\left[\begin{array}{ll}\mathrm{g}(\mathrm{x}) & \operatorname{ad}_{\mathrm{f}} \mathrm{g}(\mathrm{x})\end{array}\right]$ as well as matrix

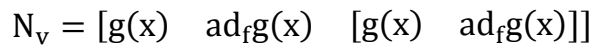

It is obvious that the rank of

$$
\mathrm{N}=\left[\mathrm{g}(\mathrm{x}) \quad \operatorname{ad}_{\mathrm{f}} \mathrm{g}(\mathrm{x})\right]=\left[\begin{array}{cc}
0 & 0 \\
0 & \frac{1}{T_{d o}^{\prime}} \mathrm{A}_{3} \mathrm{~V} \sin x_{1} \\
\frac{1}{T_{d o}^{\prime}} & \frac{1}{T_{d o}^{\prime}} \mathrm{B}_{1}
\end{array}\right]
$$

is 2 , while that of

$$
\begin{aligned}
& \mathrm{N}_{\mathrm{v}}=\left[\begin{array}{llll}
\mathrm{g}(\mathrm{x}) & \operatorname{ad}_{\mathrm{f}} \mathrm{g}(\mathrm{x}) \quad\left[\mathrm{g}(\mathrm{x}) \quad \operatorname{ad}_{\mathrm{f}} \mathrm{g}(\mathrm{x})\right.
\end{array}\right] \\
& =\left[\begin{array}{ccc}
0 & 0 & 0 \\
0 & \frac{1}{T_{d o}^{\prime}} \mathrm{A}_{3} \mathrm{~V} \sin x_{1} & 0 \\
\frac{1}{T_{d o}^{\prime}} & \frac{1}{T_{d o}^{\prime}} \mathrm{B}_{1} & 0
\end{array}\right]
\end{aligned}
$$

is 2 as well.

This condition is also satisfied.

\section{APPENDIX III}

The algorithm [60] for deriving the output function that guarantees $\mathrm{r}=\mathrm{n}$ for a SISO nonlinear system is as follows.

Consider a general nonlinear SISO system defined as

$$
\dot{x}=\mathrm{f}(x)+\mathrm{g}(x) \mathrm{u} .
$$

The following are the steps for finding an output function that makes $r$ equal to $n$.

Step 1: Create the set

$$
\mathrm{S}=\left\{\mathrm{g}(x), \operatorname{ad}_{\mathrm{f}} \mathrm{g}(x), \operatorname{ad}_{\mathrm{f}}^{2} \mathrm{~g}(x), \cdots, \operatorname{ad}_{\mathrm{f}}^{\mathrm{n}-1} \mathrm{~g}(x)\right\},
$$

and establish the subsets $S_{1}, S_{2}, \ldots, S_{n}$, where $S_{i}$ is composed of the first i elements of $\mathrm{S}$. That is,

$$
\begin{aligned}
\mathrm{S}_{1} & =\{\mathrm{g}(x)\}, \\
\mathrm{S}_{2}= & \left\{\mathrm{g}(x), \operatorname{ad}_{\mathrm{f}} \mathrm{g}(x)\right\}, \\
\mathrm{S}_{3}= & \left\{\mathrm{g}(x), \operatorname{ad}_{\mathrm{f}} \mathrm{g}(x), \operatorname{ad}_{\mathrm{f}}^{2} \mathrm{~g}(x)\right\}, \\
& \vdots \\
\mathrm{S}_{\mathrm{n}}= & \left\{\mathrm{g}(x), \operatorname{ad}_{\mathrm{f}} \mathrm{g}(x), \operatorname{ad}_{\mathrm{f}}^{2} \mathrm{~g}(x), \cdots, \operatorname{ad}_{\mathrm{f}}^{\mathrm{n}-1} \mathrm{~g}(x)\right\} .
\end{aligned}
$$

The elements of $\mathrm{S}$ in equation (AIII.2) are determined appropriately.

Step 2: Find the vectors $\overline{\mathrm{S}}_{1}, \overline{\mathrm{S}}_{2}, \cdots, \overline{\mathrm{S}}_{\mathrm{n}} \cdot \overline{\mathrm{S}}_{\mathrm{i}}$ and all the elements of $S_{i}$ are linearly dependent. In other words, $\bar{S}_{i}$ represents a linear combination of the elements of $S_{i}$. This can be mathematically expressed as

$$
\begin{aligned}
& \overline{\mathrm{S}}_{1}+\alpha_{11}(x) \mathrm{g}(x)=0, \\
& \overline{\mathrm{S}}_{2}+\alpha_{21} \mathrm{~g}(x)+\alpha_{22} \operatorname{ad}_{\mathrm{f}} \mathrm{g}(x)=0, \\
& \overline{\mathrm{S}}_{3}+\alpha_{31} \mathrm{~g}(x)+\alpha_{32} \operatorname{ad}_{\mathrm{f}} \mathrm{g}(x)+\alpha_{33} \operatorname{ad}_{\mathrm{f}}^{2} \mathrm{~g}(x)=0, \\
& \vdots \\
& \overline{\mathrm{S}}_{\mathrm{n}}+\alpha_{\mathrm{n} 1} \mathrm{~g}(x)+\alpha_{\mathrm{n} 2} \operatorname{ad}_{\mathrm{f}} \mathrm{g}(x)+\cdots+\alpha_{\mathrm{nn}} \mathrm{ad}_{\mathrm{f}}^{\mathrm{n}-1} \mathrm{~g}(x)=0 .
\end{aligned}
$$


Step 3: Obtain the transformation function $X=P(V)$ by finding the integral curve

$$
\mathrm{P}\left(\mathrm{v}_{1}, \mathrm{v}_{2}, \cdots, \mathrm{v}_{\mathrm{n}}\right)=\Phi_{\mathrm{v}_{1}}^{\overline{\mathrm{S}}_{1}} \circ \Phi_{\mathrm{v}_{2}}^{\overline{\mathrm{S}}_{2}} \circ \cdots \circ \Phi_{\mathrm{v}_{\mathrm{n}}}^{\overline{\mathrm{S}}_{\mathrm{n}}}\left(\mathrm{X}_{0}\right) \text {. }
$$

This is done by computing sequentially

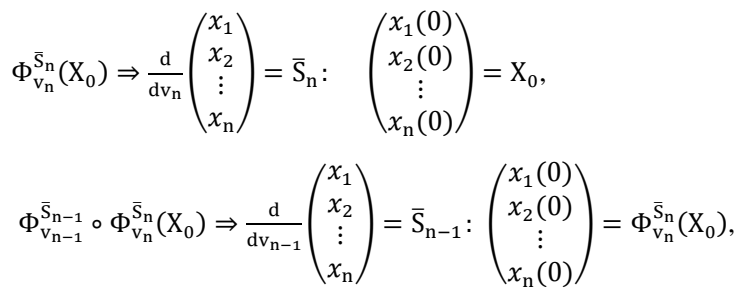

$\Phi_{\mathrm{v}_{1}}^{\overline{\mathrm{S}}_{1}} \circ \Phi_{\mathrm{v}_{2}}^{\overline{\mathrm{S}}_{2}} \circ \cdots \circ \Phi_{\mathrm{v}_{\mathrm{n}}}^{\overline{\mathrm{S}}_{\mathrm{n}}}\left(\mathrm{X}_{0}\right)$

$\Rightarrow \frac{\mathrm{d}}{\mathrm{dv}_{1}}\left(\begin{array}{c}x_{1} \\ x_{2} \\ \vdots \\ x_{\mathrm{n}}\end{array}\right)=\overline{\mathrm{S}}_{1}:\left(\begin{array}{c}x_{1}(0) \\ x_{2}(0) \\ \vdots \\ x_{\mathrm{n}}(0)\end{array}\right)=\Phi_{\mathrm{v}_{2}}^{\overline{\mathrm{S}}_{2}} \cdots \cdots \Phi_{\mathrm{v}_{\mathrm{n}}}^{\overline{\mathrm{S}}_{\mathrm{n}}}\left(\mathrm{X}_{0}\right)$.

The result of Step 3 gives

$\left(\begin{array}{c}x_{1} \\ x_{2} \\ \vdots \\ x_{\mathrm{n}}\end{array}\right)=\left(\begin{array}{c}\mathrm{P}_{1}\left(\mathrm{v}_{1}, \mathrm{v}_{2}, \cdots, \mathrm{v}_{\mathrm{n}}\right) \\ \mathrm{P}_{2}\left(\mathrm{v}_{1}, \mathrm{v}_{2}, \cdots, \mathrm{v}_{\mathrm{n}}\right) \\ \vdots \\ \mathrm{P}_{\mathrm{n}}\left(\mathrm{v}_{1}, \mathrm{v}_{2}, \cdots, \mathrm{v}_{\mathrm{n}}\right)\end{array}\right)$

from which the inverse function $\left(\begin{array}{c}\mathrm{v}_{1} \\ \mathrm{v}_{2} \\ \vdots \\ \mathrm{v}_{\mathrm{n}}\end{array}\right)=\left(\begin{array}{c}\mathrm{P}_{1}^{-1}\left(x_{1}, x_{2}, \cdots, x_{\mathrm{n}}\right) \\ \mathrm{P}_{2}^{-1}\left(x_{1}, x_{2}, \cdots, x_{\mathrm{n}}\right) \\ \vdots \\ \mathrm{P}_{\mathrm{n}}^{-1}\left(x_{1}, x_{2}, \cdots, x_{\mathrm{n}}\right)\end{array}\right)$

could be found. $\mathrm{v}_{\mathrm{n}}$ is actually the function being sought.

\section{REFERENCES}

[1] P. L. Dandeno, A. N. Karas, K. R. McClymont, and W. Watson, "Effect of high-speed rectifier excitation systems on generator stability limits," IEEE Trans., PAS, vol. 87, pp. 190-196, 1987.

[2] L. Hajagos, "An update on power system stabilization via excitation control," in Power Engineering Society General Meeting, IEEE, vol. 3, p. 1757, 2003.

[3] F. P. DeMello, L. N. Hannet, and J. M. Undrill, "Practical approach to supplementary stabilizing from accelerating power," IEEE Trans., PAS, vol. 97, pp. 1515-1522, 1978.

[4] A. A. Ghandakly and A. M. Farhoud, "A parametric optimized self-tuning regulator for power system stabilizer," IEEE Trans. On Power Systems, vol. 7, 1992.

[5] E. Irvin, J. P. Barret, C. Charcossey, and J. P. Monville, "Improving Power Network Stability and Unit Stress with Adaptive Generator Control," Automatica, vol. 15, pp. 31-46, 1979.

[6] R. Kasturi and P. Doraraju, "Relative Dynamic Stability Regions of Power Systems," IEEE Trans., PAS, vol. 89, pp. 966-974, May/June 1970.

[7] P. Kundur, M. Klein, G. R. Rogers, and M. S. Zywno,
"Application of Power System Stabilizers for Enhancement of Overall System Stability," IEEE Trans., Power Systems, vol. 4, May 1989.

[8] E. V. Larsen and D. A. Swann, "Applying Power System Stabilizers," IEEE Trans., PAS, vol. 100, pp. 3017-3046, 1981.

[9] C. M. Lim and S. Elangovan, "Design of Stabilizers in Multi-machine Power Systems," Proc. IEE, vol. 132, pp. 146-153, May 1985.

[10] Y. N. Yu and H. A. M. Moussa, "Optimal Stabilization of a Multi-machine System," IEEE Trans., PAS, pp. 1114-1182, May/June 1972.

[11] T. Sadamoto, A. Chakrabortty, T. Ishizaki, and J. Imura, "Dynamic Modelling, Stability, and Control of Power Systems with Distributed Energy Resources," IEEE Control System Magazine, vol. 39, no. 2, pp. 34$65,2019$.

[12] H. Huerta, G.L. Alexander, and M. C. Jose, "Robust multimachine power systems control via high order sliding modes," Electric Power Systems Research, vol. 81, pp. 1602-1609, 2011.

[13] D. A. Pierre, "A Perspective on Adaptive Control of Power Systems," vol. PWRS-2, pp. 387-396, May 1987.

[14] A. Ghandakly and P.Kronegger, "An Adaptive TimeOptimal Controller for Generating Units Stabilizer Loops," vol. 2, pp. 1085-1090, Nov. 1987.

[15] W. Gu and K. E. Bollinger, "A Self-tuning Power System Stabilizer for Wide-Range Synchronous Generator Operation," IEEE Trans. Power Systems, vol. 4, pp. 1191-1198, Aug. 1989.

[16] J. Kanniah, O. P. Malik, and G. S. Hope, "Excitation Control of Synchronous Generators using Adaptive Regulators Part I- Theory and Simulation Results," IEEE Trans. Power Apparatus and Systems, vol. 103, pp. 897-903, May 1984.

[17] C. J. Wu and Y. Y. Hsu, "Design of Self-tuning PID Power System Stabilizer for Multi-machine Power Systems," IEEE Trans. Power Systems, vol. 3, pp. 1059-1064, Aug. 1988.

[18] A. Ghandakly and J. J. Dai, "An Adaptive Synchronous Generator Stabilizer Design by Generalized Multivariable Pole Shifting (GMPS) Technique," IEEE Trans. Power Systems, vol. 7, Aug. 1992.

[19] C. M. Falkner and B. S. Hech, "A Comparison of Nonlinear Controllers on a Single Generator-Infinite Bus Power System," in Proceedings of the American Control Conference, Seattle, Washington, June 1995.

[20] Y. L. Abdel-Magid, M. A. Abido, S. Al-Baiyat, and A. H. Mantawy, "Simultaneous Stabilization of Multimachine Power Systems via Genetic Algorithms," IEEE Trans. Power Systems, vol. 14, Nov. 1999. 
[21] H.K. Khalil. Nonlinear Control (Global ed.): Pearson Education Ltd., England, 2015.

[22] C. F. Lin, Advanced Control Systems Design: Prentice-Hall, Englewood Cliffs, NJ, 1964.

[23] J. W. Chapman, M. D. Ilic, and C. A. King, "Stabilizing a Multi-machine Power Systems via Decentralized Feedback Linearizing Excitation Control," IEEE Trans. Power Systems, vol. 8, pp. 830838, 1993.

[24] W. Mielczarski and A. M. Zajaczkowjki, "Nonlinear Field Voltage Control of a Synchronous Generator using Feedback Linearization," Automatica, vol. 30, pp. 1625-1630, 1994.

[25] M. Nambu and Y. Ohsawa, "Development of an Advanced Power System Stabilizer using a Strict Linearization Approach," IEEE Trans. Power Systems, vol. 11, pp. 813-818, 1996.

[26] Y. Sun and Q. Lu, "Decentralized Excitation Control by Feedback Linearization," in Proceedings of the IEEE Winter Meeting, Baltimas, Maryland, USA, 1996.

[27] D. Gan, Z. Qu, and H. Cai, "Multi-machine Power System Excitation Control Design via Theories of Feedback Linearization Control and Nonlinear Robust Control," International Journal of Systems Science, vol. 31, pp. 519-527, 2000.

[28] M. A. Mahmud, M. J. Hossain, H. R. Pota, and M. S. Ali, "Generalized Lyapunov Function for Stability Analysis of Interconnected Power Systems," presented at the Universities Power Engineering Conference (AUPEC), 2011 21st Australasian, Sep. 2011.

[29] A. A. Awelewa, I. A. Samuel, A. Abdulkareem, and S. O. Iyiola, "An Undergraduate Control Tutorial on Root Locus-Based Magnetic Levitation System Stabilization," International Journal of Engineering \& Computer Science IJECS-IJENS, vol. 13, pp. 22-30, Feb. 2013.

[30] G. Espinosa-Perez, M. G. Alcantar, and G. G. Ramirez, "Passivity-Based Speed Control of Synchronous Generators," IEEE International Symposium on Industrial Electronics, vol. 1, pp. 101106, 1997.

[31] C. M. Falkner and B. S. Heck, "Design of PassivityBased Output Feedback Controller for Power System Stabilization," presented at the Proceeedings of 39th IEEE Conference on Decision and Control, Dec. 2000.

[32] J. Katende and A. A. Awelewa, "A Sliding Mode Controller for Synchronous Generator Excitation," presented at the International Conference and Exhibition on Power and Telecommunications (ICEPT): Deployment of Innovative Energy and Telecommunications Infrastructures for Regional Integration, Lagos, Nigeria, Oct. 2007.

[33] Q. Lu and Z. Xu, "Decentralized Nonlinear Optimal
Excitation Control," IEEE Trans. Power Systems, vol. 11, pp. 1957-1962, Nov. 1996.

[34] B. K. Mukhopadhyay and M. F. Malik, "Optimal Control of Synchronous Machine Excitation by Quasilinearization Techniques," IEEE Proceedings, vol. 119, pp. 91-98, 1972

[35] A. Pogromsky, A. Fradkov, and D. Hill, "PassivityBased Damping of Power System Oscillations," presented at the Proceedings of the CDC, Dec. 1996.

[36] J. Roberts and A. Ian, "Lyapunov Functions for Multimachine Power Systems with Dynamic Loads," IEEE Trans. Circuits and Systems, vol. 44, pp. 796-812, 1997.

[37] V. G. D. C. Samarasinghe and N. C. Pahalawatha, "Design of Universal Variable Structure Controller for Dynamic Stabilization of Power Systems," IEE Proceedings on Generation, Transmission, and Distribution, vol. 141, pp. 363-368, July 1994.

[38] K. Ogata, Modern Control Engineering, Third ed.: Prentice Hall, Upper Saddle River, New Jersey, 1997.

[39] Y. Rui, Y. D. Zhao, T. K. Saha, and M. Rajat, "A power system nonlinear adaptive decentralized controller design," Automatica, vol. 46, 330-336, 2010 .

[40] A. C. Zolotas, B. Chaudhuri, I. M. Jaimoukha, and P. Korba, "A Study on LQG/LTR Control for Damping Inter-area Oscillations in Power Systems," IEEE Transaction on Control System Technology, vol. 15, no. 1, 151-160, 2007.

[41] E. Jain, A. Chakrabortty, and E. Biyik, "An Online Structurally Constrained LQR Design for Damping Oscillations in Power Networks," Proc. American Control Conf., pp. 2093-2098, 2017.

[42] F. V. Juan, and L. Gerald, "Variable structure control for power systems stabilization," International Journal of Electrical and Energy Systems, vol. 32, pp. 101107, 2010.

[43] G. Rinaldi, M. Cucuzzella, and A. Ferrara, "Third Order Sliding Mode Observer-based Approach for Distributed Optimal Load Frequency Control," IEEE Control System Letter, vol. 2, no. 1, pp. 215-220, 2017.

[44] A. Colbia-Vega, J. de Leon-Morales, L. Fridman, O. Solas-Pena, and M. T. Mata-Jimenez, "Robust excitation control design using sliding-mode technique for multimachine power systems," Electric Power Systems Research, vol. 78, pp. 1627-1634, 2008.

[45] H. Huerta, G. L. Alexander, and M. C. Jose, "Decentralized sliding mode block control of multimachine power systems," International Journal of Electrical Power and Energy Systems, vol. 32, 1-11, 2010. 
[46] K. Atabak, and S. Saeed, "Application of Sliding Mode Control in Single Machine Infinite Bus System (SMIB)," Australian Journal of Basic and Applied Sciences, vol. 6, no. 5, pp. 165-174, 2012.

[47] Z. Ping, Z. Jiebin, L. Zhenxing, Y. Wei, and W. Shaorong, "Design of a Nonlinear Excitation Controller using Synergetic Control Theory," IEEE (978-1-4799-7537-2/14), 2014.

[48] D. K. Chaturvedi and O. P. Malik, "Generalized Neuron-Based Adaptive PSS for Multi-machine Environment," IEEE Trans. Power Systems, vol. 20, Feb. 2005.

[49] Y. Zhang, G. P. Chen, O. P. Malik, and G. S. Hope, "Artificial Neural Network Power System Stabilizer in Multi-machine Power System Environment," IEEE Trans. Energy Conversion, vol. 10, pp. 147-155, 1995.

[50] Y. Zhang, G. P. Chen, O. P. Malik, and G. S. Hope, "An Artificial Neural Network-Based Adaptive Power System Stabilizer," IEEE Trans. Energy Conversion, vol. 8, pp. 71-77, March 1993.

[51] Y. Zhang, G. P. Chen, O. P. Malik, and G. S. Hope, "A multi-input Power System Stabilizer Based on Artificial Neural Networks," presented at the Proceedings IEEE WESCANEX93, Saskatoon, SK, Canada, May 1993.

[52] S. K. Yee and J. V. Milanovic, "Fuzzy Logic Controller for Decentralized Stabilization of Multimachine Power Systems," IEEE Trans. Fuzzy Systems, vol. 16, Aug. 2008.

[53] G. Venkatesh, and P. K. Rao, "Improvement of Dynamic Stability of a Single Machine Infinite-Bus Power System using Fuzzy Logic based Power System Stabilizer," International Journal of Engineering Research and Development, vol. 4, no. 5, 60-70, 2012.

[54] A. Garima, M. Lini, and S. Chatterji, "MATLAB/Simulink Based Simulation of an Hybrid Power Flow Controller," Proceedings of 2014 Fourth International Conference on Advanced Computing \& Communication Technologies, pp. 523-531, 2014.

[55] C. Shuji, L. Jiang, W. Yao, and Q. H. Wu, "Application of Switched System Theory in Power System Stability," IEEE (978-1-4799-6557-1/14), 2014.

[56] L. Yun, H. A. Kiam, and C. Y. C. Gregory, "Patents, Software, and Hardware for PID Control: An Overview and Analysis of the Current Art," IEEE Control Systems Magazine, pp. 42-54, 2006.

[57] P. M. Anderson and A. A. Fouad, Power Control and Stability: The IEEE Press, New Jessey, USA, 2003.

[58] G. Fusco and M. Russo, "Controller Design for Voltage Regulation and Stabilization in Multimachine Power Systems," presented at the 2012 20th Mediterranean Conference on Control and Automation, Barcelona, Spain, July 2012.
[59] M. A. Arjona, R. Escarela-Perez, G. Espinosa-Perez, and J. Alvarez-Ramirez, "Validity testing of thirdorder nonlinear models for synchronous generators," Electric Power Systems Research, 79, 953-958, 2009.

[60] A. Isidori, Nonlinear Control Systems: An Introduction, Third ed.: Springer-Verlag, New York, 1995.

[61] A. Levant, "Universal SISO Sliding Mode Controllers with Finite-Time Convergence," IEEE Trans. Automatic Control, vol. 46, pp. 1447-1451, 2001.

[62] A. Levant, "Homogeneity approach to high-order sliding mode design," Automatica, vol. 41, pp. 823830, 2005.

[63] S. Bhat and D. Bernstein, "Geometric Homogeneity with Applications to Finite Time Stability," Math. Control, Signals Systems, vol. 17, pp. 101-127, 2005.

[64] P. W. Sauer, S. Ahmed-Zaid, and P. V. Kokotovic, "An Integral Manifold Approach to Reduced-Order Dynamic Modeling of Synchronous Machines," IEEE Trans. Power Systems, vol. 3, pp. 17-23, 1988.

[65] A. A. Awelewa, C. O. A. Awosope, A. Abdulkareem, and I. A. Samuel, "Nonlinear Excitation Control Laws for Electric Power System Stabilization," Journal of Engineering and Applied Sciences, vol. 11, no. 7, 1525-1531, 2016. 